\title{
Seed Funds Leverage External Awards for Research in Natural Resources and Agricultural Systems
}

\author{
John M. Davis ${ }^{1, * \mathbb{C}}$, Pamela S. Soltis ${ }^{2}{ }^{\mathbb{D}}$, Damian C. Adams ${ }^{1} \mathbb{(}$, Sherry L. Larkin ${ }^{1}$ \\ and Robert A. Gilbert ${ }^{1}$ \\ 1 UF/IFAS Dean for Research Office, University of Florida, Gainesville, FL 32611, USA; \\ dcadams@ufl.edu (D.C.A.); slarkin@ufl.edu (S.L.L.); ragilber@ufl.edu (R.A.G.) \\ 2 Florida Museum of Natural History, and UF Biodiversity Institute, University of Florida, \\ Gainesville, FL 32611, USA; psoltis@flmnh.ufl.edu \\ * Correspondence: jmdavis@ufl.edu
}

Received: 19 November 2019; Accepted: 2 January 2020; Published: 8 January 2020

\begin{abstract}
In the United States, "seed fund" programs in biomedical fields have been reported to enhance faculty success in securing federal awards. Seed funds are relatively small internal grants that are allocated by universities to their faculty to invigorate research, in anticipation that they will lead to larger benefits-these benefits could be the creation of stronger teams that lead to larger external grants and/or more impactful publications. We hypothesized that a seed funding approach for research on natural resources and agricultural systems, including forest systems, may have similar benefits. Here, we report that seed funding supported faculty development in numerous ways, including leveraging to generate external competitive awards. For each dollar of institutional investment in each of the three seed funding programs, faculty acquired $\$ 6,>\$ 50$, and $\$ 4.50$, respectively, in external funding that was leveraged within three years of the seed fund award date. Notably, the majority of the leveraged funding was from federal granting agencies through competitive programs. Federal competitive awards are important elements of tenure and promotion dossiers, as they reflect success in acquiring grants that are difficult to obtain, thus providing evidence of research excellence. We speculate that the seed fund proposal review process prepared faculty for competitive awards. Finally, we suggest best management practices for the implementation of seed funding to support teams of faculty.
\end{abstract}

Keywords: start-up funds; seed funds; strategic investment; team science

\section{Introduction}

Universities typically invest in new faculty programs through so-called "start-up funding" negotiated as part of the employment contract between the faculty member and the university. Start-up funding has significant benefits for junior faculty by allowing them to recruit their first graduate students and post-docs, travel to conferences to build their reputations, and equip their labs. However, start-up funding has some limitations as a career development tool, in that it is not reflected in tenure and promotion dossiers because it is not considered a funded award. In addition, start-up funding must typically be spent within a few years, which may be prior to junior faculty receiving actionable feedback on their federal grant applications.

Faculty success in securing federal awards can be enhanced through "seed fund" programs. Seed funds are relatively small internal grants that are allocated by universities to their faculty in anticipation that they will lead to larger benefits. Seed funding programs vary greatly in scope, scale and emphasis within and among universities. There are reports in the literature that seed funding programs in biomedical fields can lead to greater success by faculty who prepare and submit grant proposals for competitive programs at federal granting agencies [1,2]. Some of this success is attributed to the 
seed funding process, which may promote preparedness by increasing preliminary data, enabling the assembly of a more effective research team, and/or obtaining preliminary review of the proposal prior to submission. We hypothesized that a seed funding approach in forest research may have similar benefits. Here, we report the results of three experimental seed fund programs to support faculty development and suggest best management practices for their implementation.

\section{Study Design}

Our empirical data imply that seed funds create leveraging opportunities for faculty to more favorably compete for federal awards. We quantified the leveraging of seed funding programs that were targeted to bolster institutional preeminence in forest research, after three-year evaluation periods. An important review criterion for all proposals submitted to these programs was the submission of one or more grant proposals to one or more federal funding agencies. Each proposal contained a detailed plan for how seed funds would be leveraged in this way, including targeted agencies, programs, tentative proposal titles, and identification of faculty teams with areas of responsibility for the collection of preliminary data.

To quantify leveraging for the first and second programs, we used the university awards database to identify external grants and contracts (i.e., potential leveraged awards) awarded to faculty within the three-year monitoring period, then consulted with the individual faculty member to assess the linkage between their seed award and the external award. If there was a close linkage between seed fund deliverables and the proposal for the external award, the external award was considered leveraged.

To quantify leveraging for the third program, we relied on a qualitative, anonymous, voluntary survey of all faculty applicants for the seed funding $(\mathrm{N}=98)$, which was designed to evaluate the efficacy of the seed fund program by exploring the amount of leveraging and the reasons for faculty success in leveraging. The response rate to the survey was $58 \%$ (i.e., $\mathrm{N}=57$ respondents), with 49 respondents receiving seed funds. Of these seed fund recipients, 18 reported receiving external leveraged funding, with 15 reporting funding amounts; the funding amounts reported averaged $\$ 772,510$ per seed fund award. A total of eight respondents did not receive seed funds, with three reporting leveraged funding that averaged $\$ 63,333$ per faculty member. Total leveraging for the program was calculated by dividing the total leveraged awards from the 15 faculty after three years or less since the awards, divided by the total investment in the seed fund program during the period in which faculty received seed funds.

\section{Results}

The first program was strategically geared to enhance forest ecosystem research, emphasizing activities at the University of Florida's Ordway-Swisher Biological Station, Melrose, FL. We did not dictate the size of the awards, and as such faculty teams requested variable amounts of funding. In the first year of the program, we awarded nine seed grants, ranging from $\$ 21,808$ to $\$ 116,352$ (median seed fund award of $\$ 43,298$ ) to a total of 25 faculty (nine Principal Investigators, 16 Co-Principal Investigators) from nine different academic departments. Awardees included a balance of junior faculty who were pre-tenure (13) and senior faculty who were post-tenure (12). At the end of the evaluation period, faculty had secured $\$ 6$ in external funding for every $\$ 1$ invested in seed funding, with $73 \%$ of the external funds awarded by federal agencies. This 6:1 ratio is the total awards leveraged (plotted by award on the $y$-axis) divided by the total seed fund amount (plotted by award on the $x$-axis).

Since the seed fund awards for this first program differed in size, we could explore relationships between seed fund award size, and leveraged external award size. With this limited data set, we noted a positive correlation between seed fund award size and leveraged award size $\left(R^{2}=0.89\right)$ with an $x$-intercept of $\$ 29,421$ denoting the minimum seed fund amount that generated positive leverage (Figure 1). While we hesitate to over-interpret these limited data, they imply that very small seed grants are limited in their effectiveness in leveraging external awards. Continued monitoring of the program will be needed to determine if these values are robust. 


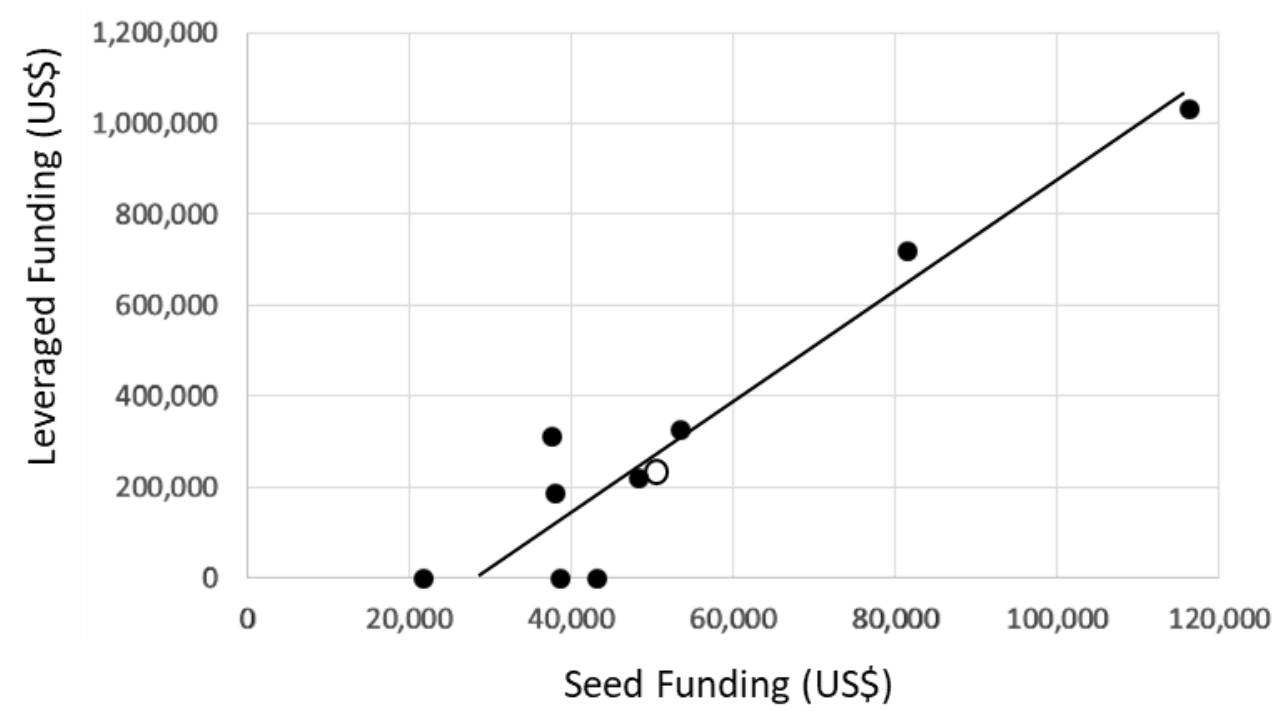

Figure 1. Positive correlation between seed funding ( $x$-axis) and leveraged external awards ( $y$-axis) in the first program (solid circles) and the third program (open circle). The best fit regression line is shown, with the $x$-intercept representing the break-even point for positive leveraging.

The second program was strategically geared toward enhancing the research enterprise of the newly-created University of Florida Biodiversity Institute. At the end of the evaluation period, faculty had secured $\$ 52$ in external funding for every $\$ 1$ invested in seed funding, with $100 \%$ of the external funds awarded by federal agencies. The large value of leveraging was due primarily to one major grant $(>\$ 7 \mathrm{M})$ focused on a forest tree species that was awarded to an intercollegiate faculty team. Most seed fund awardees were not successful in leveraging their seed funds within three years, however the one major award created a large amount of leveraging for the overall seed fund program. This illustrates that there can be ample justification to continue a seed fund program despite an overall low success rate of leveraging within a narrow assessment window.

The positive leveraging noted in these two programs is on par with self-reported data from a survey of early-career applicants to a third seed funding program, in which we asked faculty to specifically link results from their seed funds to the acquisition of preliminary data leading to external funding. This program was broadly targeted to enhance research in agriculture, natural resources, and interrelated human systems. Award size was $\$ 50,000$ for pre-tenure faculty only. At the end of the evaluation period, the faculty respondents reported that they had secured $\$ 4.50$ in external funding for every $\$ 1$ invested in the seed fund program (Figure 1). It is notable that greater than $90 \%$ of the external funding was from federal agencies (52\% from United States Department of Agriculture-National Institute of Food and Agriculture, 24\% from National Institutes of Health, and 15\% from National Science Foundation). These are encouraging statistics because it implies that the seed fund program enhanced the preparedness of early-career faculty to secure funding from highly competitive sources.

\section{Conclusions and Best Practices}

As a complement to start-up funding, "seed fund" programs can be worthwhile investments in that they can: (1) Foster development of early drafts of future grant proposals to federal agencies, as a requirement detailed in the announcement; (2) Be competitively awarded through a process patterned after federal grant panel review processes, with feedback provided to strengthen future applications; (3) Create incentives for, and reward, faculty at all career stages, including those at early career stages who are in the process of onboarding, or in the tenure and promotion evaluation process; (4) Motivate faculty to join nascent inter-, multi-, and/or trans-disciplinary teams of faculty, potentially across multiple academic units; and (5) Recruit faculty to submit proposals focused on strategic research initiatives of the university. Seed funding is therefore complementary to start-up funding in that it can 
accomplish strategic objectives and promote returns on investment [3] including increased leveraging, and can do so within a relatively short time frame.

Competitively awarded seed funding programs can help prepare faculty to compete for external awards from federal agencies. Acquisition of competitive awards as a Principal Investigator from federal agencies is a significant milestone for many junior faculty, as it is an important line of evidence for research excellence in tenure and promotion dossiers. Seed funds for research in natural resources and agricultural systems, as in biomedical sciences, can supplement traditional start-up funding, galvanize team science, build institutional strengths, support faculty development at all career stages, and maximize return on public investment.

Author Contributions: J.M.D., P.S.S., D.C.A., S.L.L. and R.A.G. contributed conception and design of the study. J.M.D. wrote the first draft of the manuscript. All authors contributed to manuscript revision, read and approved the submitted version. All authors have read and agreed to the published version of the manuscript.

Funding: The seed awards described in this work were funded in part by USDA-NIFA capacity funds, and in part by facilities and administrative (F\&A) costs recovered by the Florida Agricultural Experiment Station, the office of the Senior Vice President for Agriculture and Natural Resources, and the Office of Research, University of Florida.

Conflicts of Interest: The authors declare no conflict of interest.

\section{References}

1. Kulage, K.M.; Larson, E.L. Intramural pilot funding and internal grant reviews increase research capacity at a school of nursing. Nurs. Outlook 2018, 66, 11-17. [CrossRef]

2. Paller, M.S.; Cerra, F.B. Investing in research: the impact of one academic health center's research grant program. Acad. Med. 2006, 81, 520-526. [CrossRef] [PubMed]

3. Preuss, M. Return on investment and grants: A review of present understandings and recommendations for change. Res. Manag. Rev. 2016, 21, 1-26.

(C) 2020 by the authors. Licensee MDPI, Basel, Switzerland. This article is an open access article distributed under the terms and conditions of the Creative Commons Attribution (CC BY) license (http://creativecommons.org/licenses/by/4.0/). 